\title{
A PERÍCIA CONTÁBIL NO PROCESSO DO TRABALHO
}

Irene Caires da Silva, Mári Ângela Pelegríni

Universidade do Oeste Paulista - UNOESTE, Faculdade de Direito, Presidente Prudente, SP. E--mail:irene@unoeste.br

\section{RESUMO}

O artigo analisa a prova técnica contábil, como um dos meios de provas, utilizadas no processo do trabalho. O objetivo do artigo é identificar as provas existentes e qual a importância da prova pericial contábil e sua indispensabilidade, ou não, no auxílio para os magistrados trabalhistas no resultado efetivo da ação trabalhista. Demonstra que, havendo necessidade, o que ocorre em casos em que envolve planilha e resultados complexos, o juiz do trabalho deve se valer dos profissionais contadores, especialistas nesta profissão, únicos autorizados a realizar esta prova pericial. $\mathrm{O}$ artigo identifica, inicialmente, os demais meios de prova para focar na perícia contábil. Utilizou-se o método indutivo, partindo do geral, para o particular, com pesquisas bibliográficas. Conclui que o laudo pericial contábil é indispensável em ações trabalhistas complexas, a ser realizado por profissional habilitado.

Palavras-Chave: Prova. Perícia. Contábil. Quesitos. Laudo

\section{THE EXPERTISE IN ACCOUNTING PROCESS WORK}

\begin{abstract}
The article analyzes the technical accounting evidence, as a means of evidence used in the work process. The objective of this article is to identify the existing evidence and the importance of accounting evidence and its indispensability or not the aid for labor judges in the effective result of labor action. It demonstrates that there is a need, which occurs in cases involving sheet and results of complex calculations, the labor court must take advantage of professional accountants, experts in this profession, only authorized to carry out this expert evidence. The article identifies initially other evidence to focus on forensic accounting. We used the inductive method starting from the general to the particular, literature searches. It concludes that the accounting expert report is necessary in complex labor, to be performed by a qualified professional.

Keywords : Proof. Expertise. Accounting. Questions. Report
\end{abstract}




\section{INTRODUÇÃO}

A pesquisa, após as noções fundamentais sobre os meios de prova no processo do trabalho, centralizou a atenção no estudo destes meios lícitos de realização de todas as provas em Direito para depois focar na prova pericial e seus limites.

Após a análise de como se processa a prova pericial na fase de conhecimento, investigou a necessidade, ou não da participação do profissional contador, único habilitado para este mister, realizando a perícia contábil judicial, como meio de trazer ao conhecimento de todos, após as devidas manifestações e impugnações, qual o valor exato que cada trabalhador, o grande litigante na esfera trabalhista, terá para receber quando credor e vitorioso numa demanda.

Observou-se que a sentença trabalhista, em sua maioria ilíquida, determina genericamente a liquidação pelos três tipos possíveis, mas a pesquisa constatou que a mais utilizada é a liquidação por cálculos.

Quando simples, a Justiça do Trabalho conta com a assessoria de cálculos, mas, quando complexos, cabe a atuação do perito contador, indicado entre os profissionais de confiança do juízo.

A forma de sua atuação, os procedimentos da liquidação por cálculos, e seu trabalho na qualidade de auxiliar do juízo, foi destaque neste trabalho.

Desse modo, a prova pericial é de suma importância e indispensável no auxílio do juízo para atingir a finalidade do processo, que é entregar a cada um o que é seu, no exato valor que foi sonegado, principalmente quando da existência de cálculos muito complexos e que fogem ao entendimento dos assistentes judiciais.

A presente pesquisa tem como objetivo principal estudar os tipos de provas permitidos pelo direito do trabalho, com foco na perícia contábil.

\section{METODOLOGIA}

O trabalho se apoiou em pesquisas bibliográficas, em doutrina especializada e na legislação em vigor. Utilizou-se o método hipotético-dedutivo indo do conhecimento geral das ciências jurídicas, sem desprezar o caráter técnico dos conhecimentos advindos das ciências contábeis, focando a prova pericial na área trabalhista. As informações sobre o tema foram analisadas de forma dialética, de modo a comprovar a necessidade, ou não, de nomeação do perito contábil nas ações trabalhistas e em que situações.

\section{RESULTADO}

Os peritos contábeis necessitam de formação das ciências contábeis para poder auxiliar os juízes em cálculos complexos. A formação adicional em Direito do Trabalho poderá ser uma vantagem individual para esses profissionais, mas não indispensável, pois nada se identificou a esse respeito na doutrina.

Os cálculos realizados por peritos contadores e seu trabalho, em certos casos mais complexos, indispensáveis, pois só ele tem a formação adequada, irá conduzindo o magistrado a um julgamento mais justo na resolução/decisão de uma lide, já em sua fase final.

É que, serão apresentados quesitos, existirá a possibilidade de impugnação, em amor ao princípio do contraditório, e, ao final, o juiz irá homologar o cálculo mais próximo daquilo que decidiu na sentença.

Dessa forma, a prova pericial sempre dependerá da nomeação de um juiz, sendo um especialista contábil, podendo ser este ato determinado tanto na fase de conhecimento como na execução.

Neste sentido, para que esses profissionais sejam nomeados, basta a entrega de currículos com a comprovação de suas experiência profissional e escolar, bem como comprovar estar apto e sem nenhum impedimento ou suspeição para o exercício da profissão. 
A Justiça do Trabalho não tem em seus quadros peritos próprios, eles precisam se oferecer ou ser convidados para trabalhar, de maneira bem simples, pois não há concurso ou testes de aptidão.

Embora não haja previsão legal, alguns juízes exigem que as partes depositem os chamados honorários-prévios, de modo que o perito possa ter como cobrir as despesas básicas com seus deslocamentos iniciais para a realização dos trabalhos.

Por fim, como na Justiça do Trabalho a maioria dos trabalhadores recebem os benefícios da Justiça Gratuitas, que os isenta do pagamento dos honorários periciais, não faz muitos anos, o CNJ (Conselho Nacional de Justiça) inspirado na experiência pioneira de alguns tribunais brasileiros, principalmente do Tribunal Regional do Trabalho da 15a Região, com sede em Campinas, passaram a prever em seus orçamentos, verba anual para custear os trabalhos periciais decorrentes de perícias em que o trabalhador perde a causa, é beneficiário da justiça gratuita e o trabalho pericial foi feito.

\section{DISCUSSÃO}

No processo do trabalho vários são os meios de prova, desde a utilização da inspeção judicial, também um meio de prova, principalmente por que o juiz do trabalho tem ampla liberdade na colheita das provas (art. 765 da CLT) e não precisa aguardar qualquer requerimento da parte, sendo uma das mais importantes e pode se valer de um perito para o acompanhar em tais inspeções, como é o caso de fazer inspeção no local de trabalho, trazendo os livros contábeis e de documentos que comprovem, por exemplo, os lucros do empregador, no caso de pedido de participação nos lucros e resultados.

Dentre outros meios, os mais conhecidos meios de prova são: depoimentos pessoais, prova documental, testemunhal e pericial, além da inspeção judicial já mencionada.

DNo que diz respeito a prova denominada inspeção judicial e de acordo com a redação do Art. 481 do novo Código de Processo Civil/2015, que repetiu a redação do art. 440 do CPC de 1973: "O juiz, de ofício ou a requerimento da parte, pode em qualquer fase do processo, inspecionar pessoas ou coisas, a fim de se esclarecer sobre fato que interesse à decisão da causa."

Neste sentido, o juiz poderá sozinho, ou por opção ou necessidade ser auxiliado por um perito, inspecionar coisas ou pessoas, com a finalidade de esclarecimentos sobre determinados fatos.

Depois que uma decisão judicial não comportar mais nenhum recurso, chega a hora de descobrir qual o exato valor que o trabalhador tem para receber.

E a maioria das sentenças não são líquidas (não dizem qual o valor da condenação e remetem essa descoberta/investigação, para a fase de liquidação.

São, em sua grande maioria, ilíquidas, ou seja, não se sabe o valor do crédito, denominado quatum debeatur, expressão latina que significa: quanto se deve.

Para chegar a esse resultado, a lei prevê a existência de três formas de liquidação da sentença, antes de seu cumprimento.

De acordo com o Art. 879 da CLT sendo ilíquida a sentença exequenda, previamente, será feita a sua liquidação, que poderá ser feita por cálculo, por arbitramento ou por artigos.

A liquidação por artigos, entretanto, só pode ser solicitada pelo exequente, em face da obrigação de defender e prova de fato novo.

A liquidação do título executivo processa-se por artigos quando depende de cognição do juízo, por meio das alegações e provas de fatos novos, ou seja, de fatos que não foram alegados pelas partes no processo de conhecimento ou que o juiz, propositalmente, remeteu (CAIRO JUNIOR, 2014 p. 740). 
A liquidação por artigos, portanto, só pode ser solicitada pelo autor. Perante a sua inércia existirá incidência da prescrição intercorrente, visto que o juiz não pode praticar esse ato de ofício.

Os trâmites desta liquidação são mais complexos, pois poderá haver uma nova inicial, com os quesitos, nova instrução probatória, inclusive com colheita de dados, oitiva de testemunhas, etc.

Em muitos casos, poderá após o trâmite da liquidação por artigos, iniciar-se uma segunda fase da liquidação, dessa vez por simples cálculos.

Já a liquidação por arbitramento é usada assim como uma determinação de encontro de um parâmetro. $\mathrm{O}$ exame e a análise de livros, registros de transações e documentos, poderá servir de base para a fixação de um dado aproximado, que, por qualquer circunstância não mais exista.

A vistoria também poderá servir de diligência, que objetiva a verificação e a constatação de situação, coisa ou fato, de forma circunstancial, visando a fixação do parâmetro, fixado apenas pelo perito contábil, em se tratando de investigação numérica e em balanços, por exemplo, resultando numa comparação aproximada que servirá de norte, por exemplo, para a fixação de uma indenização.

Nesse sentido, o uso da modalidade de arbitramento da liquidação já pode fazer parte expressamente do título executivo (sentença) ou derivar da sua obrigação em razão da natureza da obrigação.

Desse modo, esse procedimento de liquidação permite na realização de exame ou vistoria pericial, onde o objeto é quantificado.

A liquidação por cálculo, que é a que nos interessa, poderá ocorrer com o título executivo judicial (sentença) ou extrajudicial (ações de cobrança) precisando de dois ou mais meios de liquidação.

Nesse caso, será feita em primeiro lugar a liquidação por artigos ou por arbitramento e, logo em seguida, a liquidação por cálculo, se for necessária (CAIRO JUNIOR, 2014).

O método de trabalho na liquidação por cálculos, a mais utilizada, será necessária quando o título executivo necessita apenas de operações aritméticas para se tornar líquido, espécie mais comum no procedimento de elaboração dos cálculos.

Destaque-se que a complexidade é dos cálculos, identificação de dados no caso concreto e não a mera atualização monetária, que é única e fácil, como explica Cairo Junior (2014 p. 742):

[...] O conselho superior da justiça do trabalho consentiu o novo preceito único de cálculo da justiça do trabalho, interligado a tabela única para atualização e conversão de débitos trabalhistas, cujo software encontra-se disponível.

Por outro lado, de acordo com o Art. $879 \S 6^{\circ}$ :

Tratando-se de cálculos de liquidação complexos, o juiz poderá nomear perito para a elaboração e fixará, depois da conclusão do trabalho, o valor dos respectivos honorários com observância, entre outros, dos critérios de razoabilidade e proporcionalidade.

Constata-se, portanto, que a própria lei define que, quando da existência de cálculos complexos, a liquidação poderá ser feita por perito.

Em Direito, a expressão "poderá", significa uma faculdade. O juiz é quem decidirá se o cálculo é complexo ou não.

A complexidade dos cálculos, porém, acabará por exigir um profissional gabaritado. 
As partes no processo terão possibilidade de impugnação, mas com o apoio do perito contábil, o juiz estará seguro para decidir a conta exata e ou mais próxima do direito do trabalhador, normalmente aquele que está no polo ativo da maioria das demandas trabalhistas.

\section{CONCLUSÃO}

O presente estudo abordou os meios de prova aplicáveis ao direito do trabalho. $\mathrm{Na}$ sequência, identificou os meios de provas em Direito admitidas.

Destacou o foco da pesquisa, confirmando a importância da perícia contábil no processo de trabalho.

Constatou que a perícia contábil na esfera judicial e extrajudicial exige conhecimento de contabilidade e não necessariamente que seja, também, um bacharel em Direito, mas certamente, se assim ocorrer, terá ainda maior facilidade em entender os termos técnicos jurídicos e melhor auxiliar o magistrado, tanto na fase de conhecimento, onde surgem inúmeras dúvidas que os impede de decidir, como na execução, para descobrir o valor líquido que o credor trabalhista tem para receber.

É imprescindível que o perito contábil siga as normas brasileiras de contabilidades e os princípios normativos para a realização do seu planejamento visando à qualidade e clareza de sua pericia contábil, contribuindo como auxiliar da justiça que é, reforçada sua importância no novo CPC, aplicável ao processo do trabalho.

No âmbito da justiça o perito deverá elaborar o laudo fundamentando com todas as técnicas contábeis, incluindo sua inscrição nos cadastros informatizados e a possibilidade de ilustração do trabalho com gráficos, fotos e áudios, para ilustrar seu trabalho, ainda mais em tempos de processo judicial eletrônico.

O assistente técnico na perícia contábil é de fundamental importância para os operadores do direito, principalmente em cálculos complexos, possibilitando um planejamento e desenvolvimento de cálculo na perícia judicial. Quanto maior o valor encontrado, melhor para todos e poderá auferir bons honorários, mormente frente às perícias de alta complexidade.

Por fim, o profissional para poder exercer a função de perito contador deverá aperfeiçoar os conhecimentos, podendo, na área do Direito que pretende atuar.

O processo do trabalho, possibilita ampliar seu campo de atuação, aumenta seu prestígio, na medida em que se esforça para a apresentação de um laudo claro, moderno e diferenciado, o que permitirá sua indicação para outros magistrados, já que, como demonstrou a pesquisa, não há concurso de peritos contadores na Justiça trabalhista, dependendo de nomeações para os trabalhos, normalmente mais complexos, uma faculdade do magistrado, tanto nas fases de conhecimento ou de execução.

\section{REFERÊNCIAS BIBLIOGRÁFICAS}

CAIRO JUNIOR, José. Curso de Direito Processual do Trabalho. 7ạ Ed. São Paulo: Jus Podivm, 2014.

LAKATOS, M. Fundamentos de Metodologia Científica. 7ạ ed. São Paulo. Atlas. 2010.

Vade Mecum / Obra Coletiva de Autoria da Editora Saraiva com a colaboração de Luiz Roberto Curia, Livia Céspede e Juliana Nicoletti - 16. ed. Atual e ampl. - São Paulo: Saraiva, 2013.

BRASIL. Consolidação das Leis do Trabalho. Lei 5.452, de 11 de janeiro de 1943. Disponível em: <www.planalto.gov.br>. Acesso em: 26 de abril de 2016. 